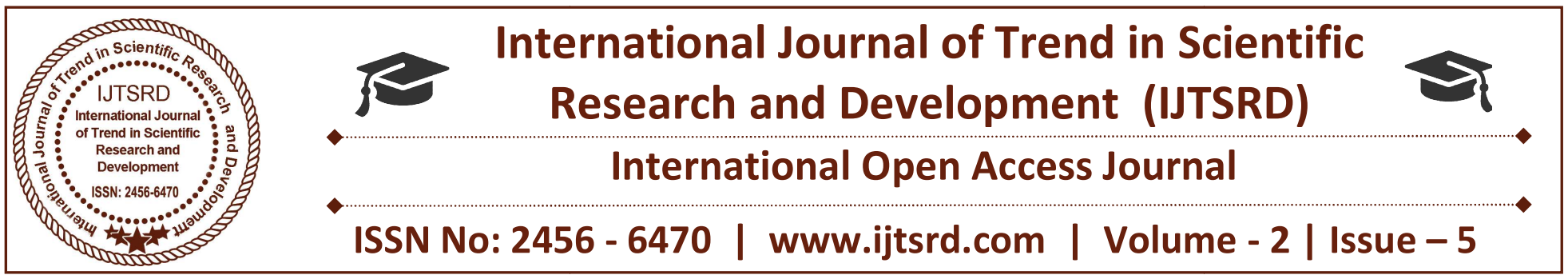

\title{
Proportional Reactive Power Sharing Using Advanced Droop Control Method
}

\author{
Miss. Priya S. Sonekar ${ }^{1}$, Sagar B. Kudkelwar ${ }^{2}$
}

${ }^{1}$ P.G. Student, ${ }^{2}$ Professor \& Head

Department of EE, Ballarpur Institute of Technology, Ballarpur, Maharashtra, India

\begin{abstract}
Microgrids are nowadays used to produce electric energy with more efficiency and advantage. However, the use of microgrids presents some challenges. One of the main problems of the microgrids widely used in electrical power systems is the control of voltage, frequency and load sharing balance among inverterbased distributed generators (DGs) in islanded mode. Droop method performance degrades when the feeder impedances of two DGs are different and thereby, further modification is required. In this paper, a new method based on virtual impedance and compensating voltage is proposed and simulation results show that this method combined with droop control results in balanced power sharing with negligible voltage and frequency drop. Simulation results have been extracted from the Simulink, MATLAB and showed that the proposed method has a good performance in equal load sharing between two DGs with different feeder impedances; both in equal and different droop gains, and with different loads such as nonlinear or unbalanced ones.
\end{abstract}

Keywords: Micro grid, Droop control, Distributed Generation, reactive power sharing, self frequency control

\section{INTRODUCTION}

The increasing high energy demand along with low cost and higher reliability requirements, are driving the modern power systems towards clean and renewable power. In small distributed generation (DG) units microgrid technologies are going to be a huge supports in power system. Microgrid dispatch clean and renewable power compared to the conventional centralized power generation. Microgrids are systems which operate with different types of loads and micro source. Distributed generation (DG) units with different types of loads can cause power quality and power control issues.

To maintain power control stability the total load demand sharing by distributed generation units should share equal load [1]. For sharing active and reactive power from multiple distributed generation units a voltage and frequency droop control methods are used. These distributed generation units are operated by inverters and DC storage units, where a number of parallel inverters are operated [2], [5]. To stabilize the system voltage and frequency all the distributed generation units are highly responsible while sharing active and reactive power in an autonomous microgrid [4]. There are many techniques presented without control interconnection in [5], [9]. Conventionally, they are based on the frequency and voltage droop concept to achieve load sharing.

The total loads must be properly shared by multiple distributed generation units in decentralized manner for an islanded microgrid [3], [5]. The reactive power sharing is sensitive to the impacts of mismatched feeder impedance while the real power sharing at steady state is always accurate [3]- [6]. In many literatures the reactive power sharing accuracy in a simplified microgrid with two distributed generation (DG) units has been introduced [7]-[9]. For a networked microgrid configuration the reactive power sharing is more challenging. To reduce the reactive power sharing errors in microgrid system, some of improved methods have been introduced [2]-[8]. The 
control issues regarding reactive power sharing in networked microgrid is more challenging. To improve reactive power sharing and control in networked microgrid, this paper proposed a simple reactive power sharing compensation scheme. .Reactive power sharing errors are significantly reduced with this proposed method. After the compensation, the proposed droop controller will be automatically switched back to conventional droop controller. The proposed compensation method achieves accurate reactive power sharing at steady-state and is effective for microgrids.

In this paper, the advanced reactive power sharing method is proposed. The method improves the reactive power sharing by changing the voltage bias, which is activated by a sequence of synchronization events through the low-bandwidth communication network. It is a cost-effective and practical approach since only a low bandwidth communication network is required. Simulation results are provided to verify the effectiveness and feasibility of the proposed reactive power sharing method [10].

\section{DISTRIBUTED GENERATION}

Distributed generations are small electric power generators. DG can be installed close to the customers because of its size and clean energy technology. Installation \& operation of electric power generation units connected to the local network or off-grid generation.

On the basis of the type and depth of penetration of distributed energy resource (DER) units, load characteristics and power quality constraints, and market participation strategies, the required control and operational strategies of a microgrid can be significantly different than those of the conventional power systems. DER units include both distributed generation (DG) and distributed storage (DS) units with different capacities and characteristics. At the low-voltage bus of the substation transformer the electrical connection point of the microgrid to the utility system, constitutes the microgrid point of common coupling (PCC) [2].

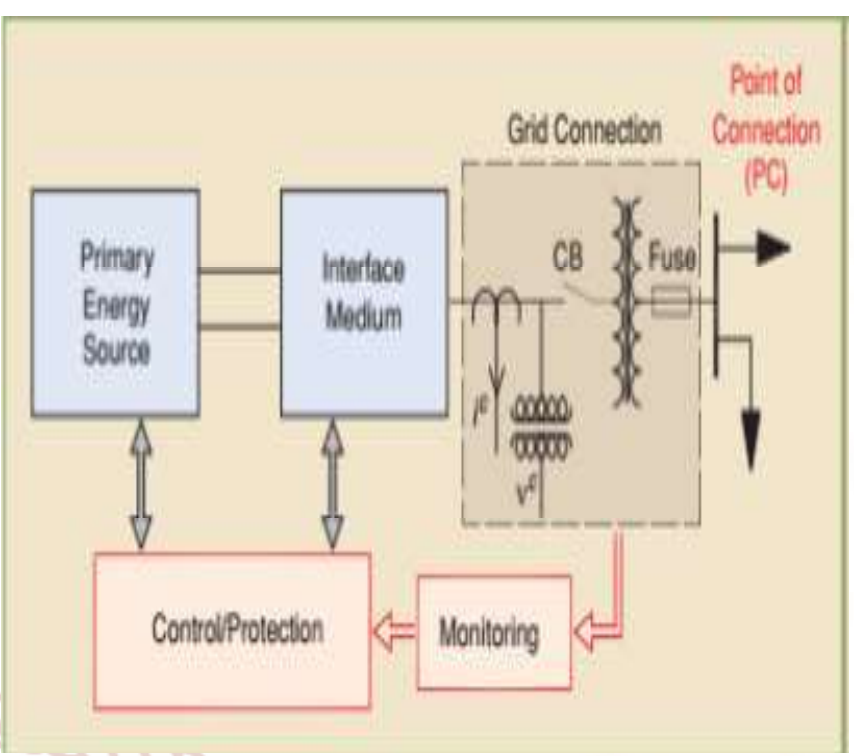

Fig.1: Basic Distributed Generation unit

\section{MICROGRID CONCEPT}

It has been suggested that the solution to the reliability, accuracy and stability issues is to take advantage of microgrid technologies. The term -"microgrid" is quickly becoming a popular topic within the power community but it still remains vaguely defined [8].According to U.S. Department of Energy Microgrid Exchange Group defines a microgrid as a group of interconnected loads and distributed energy resources (DERs) within clearly defined that acts as a single controllable entity with respect to the grid.

Compared to use a single DG unit, microgrid could offer superior power management within the distribution networks. Moreover, the microgrid can operate in grid-connected mode or islanded mode and benefit both the utility and customers in economy [12]. In an islanded mode, the load power in the microgrid should be properly shared by multiple DG units. Usually, the droop control method which mimics the behavior of a synchronous generator in traditional power system is adopted, which does not need the use of critical communications [13]-[18],

The accurate active power sharing is always simply achieved by the droop control method easily. However, due to effects of mismatched feeder impedance between the DGs and loads, the reactive power will not be shared accurately. In extreme situations, it can even result in severe circulating reactive power and stability problems [14]. 


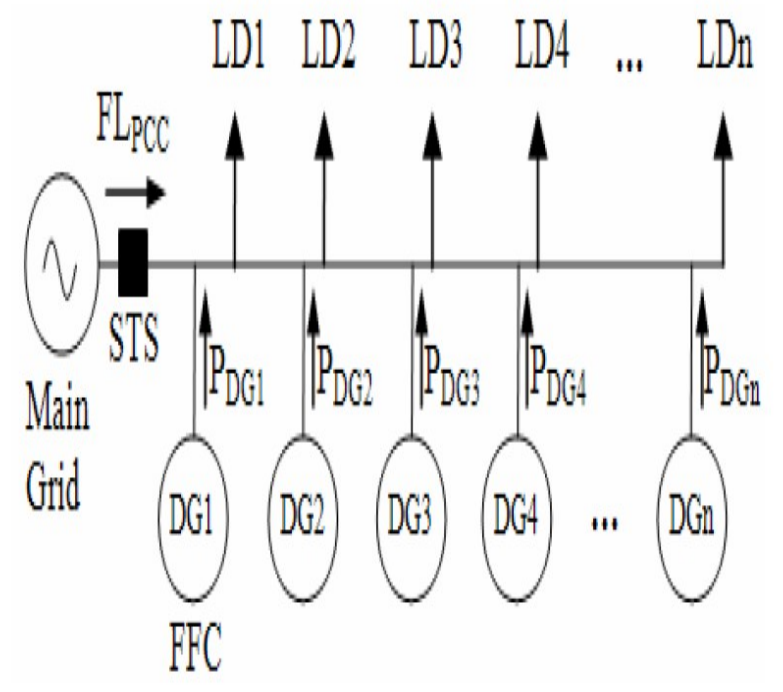

Fig 2. Architecture ofmicrogrid

The Fig. 2 shows the simplified diagram of grid connected microgrid which comprises of multiple DGs

\subsection{Modes of operation of a microgrid:}

A microgrid is connected to the utility grid through a bidirectional power converter that continuously monitors both sides and manages power flow between them [12-14]. If there is a fault in the utility grid, the power converter will disconnect the microgrid from the grid, creating an islanded energy system. Concluding, there are two operation modes for a microgrid:

\section{A. Grid Connected Mode:}

In the grid-connected operation mode, the grid-tied power converter has control over the DC link voltage level. If the output sum of the power of the distributed generation systems is sufficient to charge the storage devices, any excessive power is supplied to the utility grid.

\section{B. Islanded Mode:}

When a DC microgrid must be separated from the utility grid and switch to the is landed mode, the gridtied power converter releases control of the DC link voltage level, and one of the converters in the microgrid must take over that control. A smooth transfer between grid-connected and islanded mode is essential for the reliability of a microgrid. When grid faults occur, in order to protect the power electronic devices and some sensitive loads, the STS disconnect the microgrid from the grid.

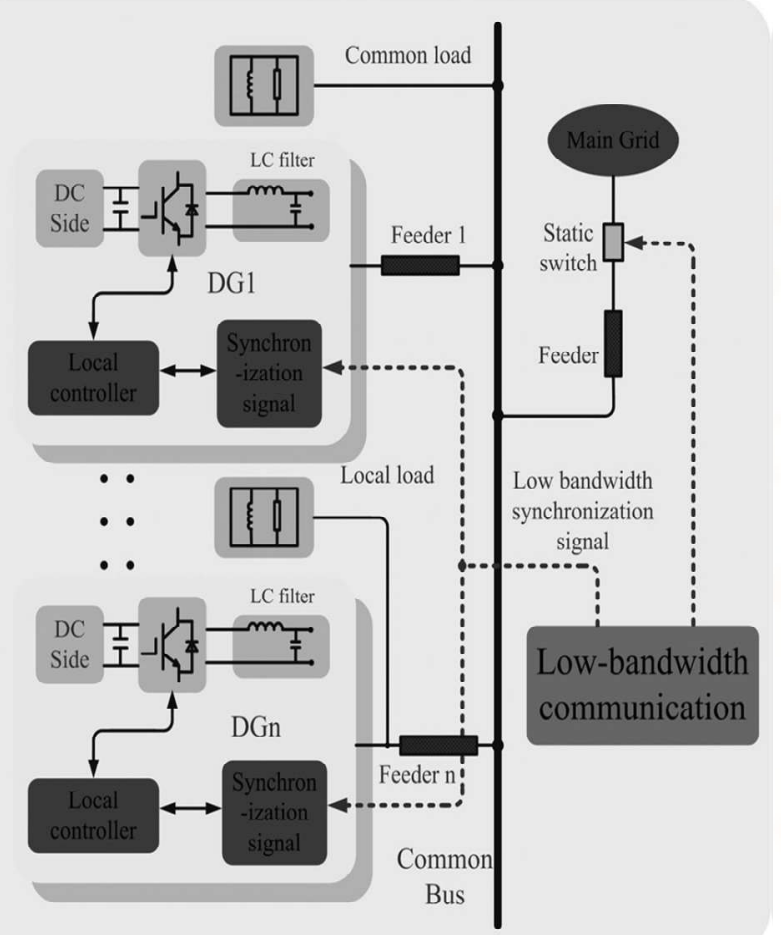

Fig 3 Illustration of the ac microgrid configuration

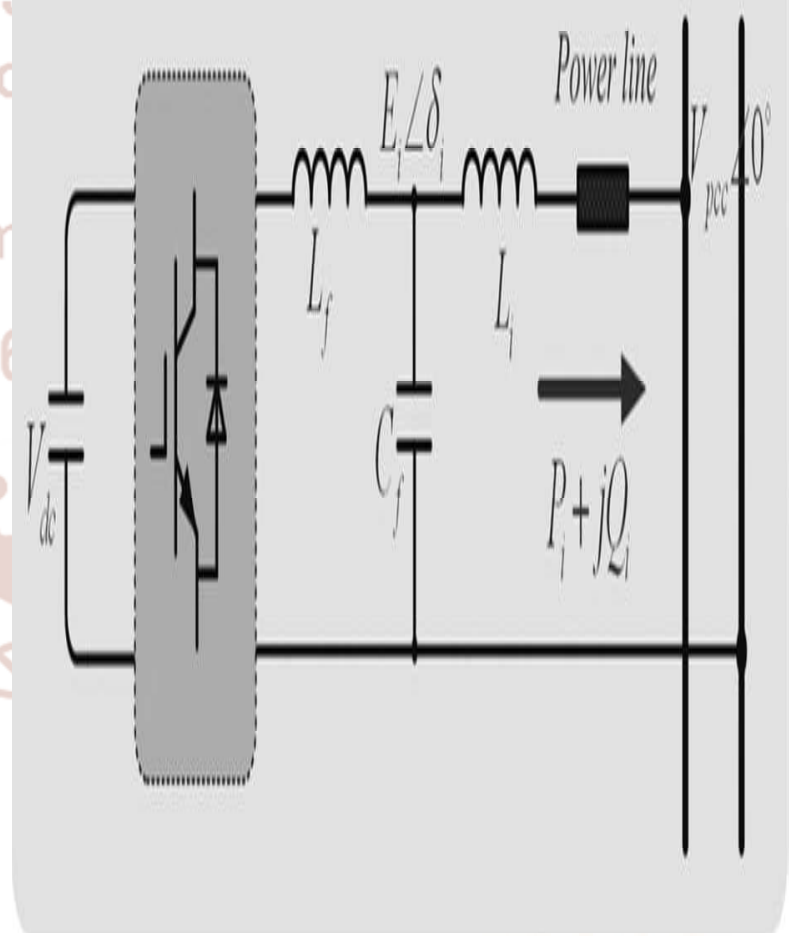

Fig.4 Model of a DG unit.

\section{PROPOSED DROOP CONTROL METHOD}

The proposed control scheme for the ith DG unit is shown in Fig. 5, where the subscript $i$ refers to the index of the DG; Pi, disandQi, dis are the dispatched values of the active and the reactive power, respectively, from the $\mathrm{CC}$; $\mathrm{Pi}$ and $\mathrm{Qi}$ are the active and the reactive output powers of the DG, 
respectively; fnom and Vnom are the nominal frequency and the voltage, respectively; fi, ref and $\mathrm{Vi}$, ref are the reference frequency and the voltage, respectively; fi is the output frequency of the DG; vabc, ref is the three-phase voltage reference input to the voltage source; $a$ and $b$ are the nodes of the switch; $\mathrm{mi}$ and $\mathrm{ni}$ are the droop coefficients of frequency droop and voltage droop, respectively; and $\mathrm{kf}$ and $\mathrm{kc}$ are the integral gains for the self-frequency recovery control and the compensation control, respectively.

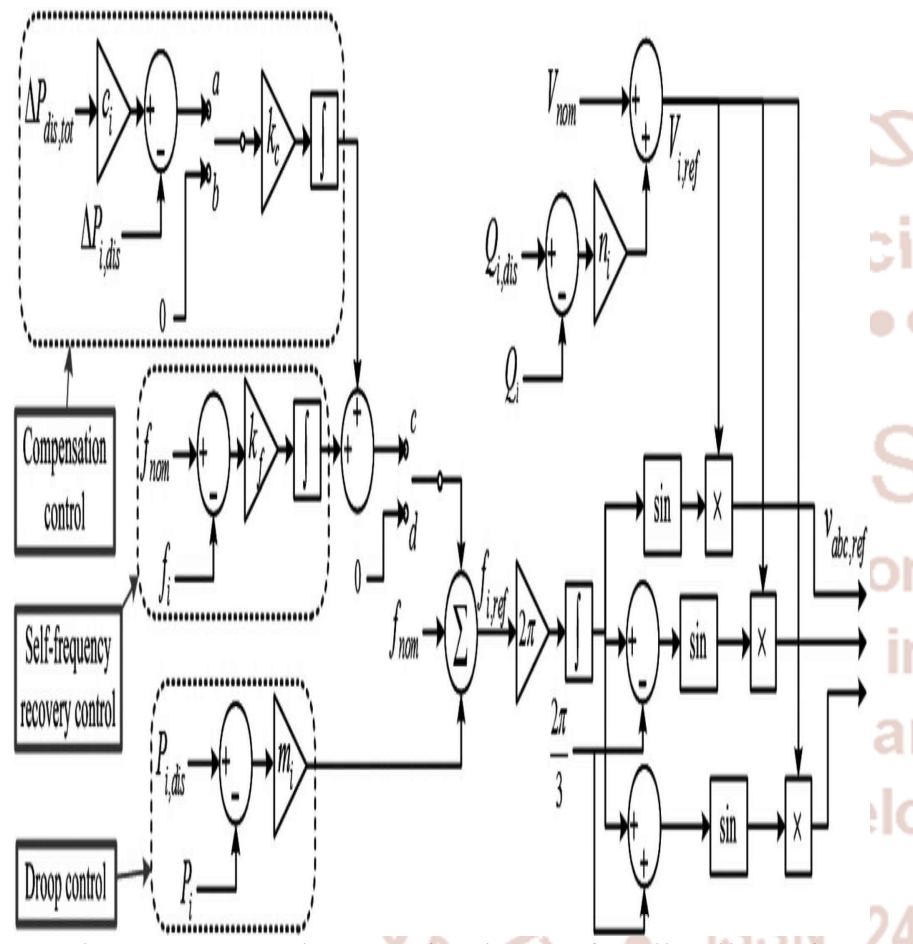

Fig.5 Proposed control scheme for distributed generation DG units.

The control method for the reactive power sharing uses conventional reactive power-voltage magnitude $(\mathrm{Q}-\mathrm{V})$ droop control. For this reason, the reference of the voltage magnitude

$\mathrm{Vi}$, ref is expressed as follows:

$\mathrm{Vi}, \mathrm{ref}=\mathrm{Vnom}+$ ni $(\mathrm{Qi}, \mathrm{dis}-\mathrm{Qi})$.

The reference voltage magnitude is determined from the deviation of the output reactive power from its dispatched value (which is usually zero with a unity power factor); therefore, the reference voltage magnitude is proportional to the $\mathrm{Q}-\mathrm{V}$ droop coefficient ni.

\section{A. Droop Control}

For basic control of active power sharing, the conventional P-f droop control was applied. The output frequency fi can be expressed as

$f i=$ fnom $+m i(P i$, dis $-P i)$.

The reference output frequency was determined from the deviation of the active power from the dispatched value (determined by the $\mathrm{CC}$ ), which is proportional to the $\mathrm{P}-\mathrm{f}$ droop coefficient $\mathrm{mi}$. without selffrequency recovery control or compensation control, the frequency deviation from the nominal value can be determined using droop control only. With droop control, the exact load sharing among DG units is proportional to the droop coefficients. This process can be implemented by exchanging the same output frequency of each DG unit in the steady state; however, because the frequency will inevitably deviate from the nominal value and must be restored according to the grid code requirements, an additional control scheme for the frequency restoration is required.

\section{B. Self-Frequency Recovery Control}

The principal objective of self-frequency recovery control is to distribute the measures required to achieve frequency recovery among the DG units that participate in active power sharing using $\mathrm{P}-\mathrm{f}$ droop control according to a predetermined ratio. The frequency restoration of the ith DG unit due to selffrequency recovery control can be expressed as

$\Delta \mathrm{fi}$, res $=\mathrm{kf} \int\left(f_{\text {nom }}-f_{i}\right) \mathrm{dt}$

Where $\mathrm{kf}$ is all the same value for every DG unit, which means that the burden of frequency restoration is shared equally among the DGs.

\section{Compensation Control}

To offset the errors in active and reactive power sharing caused by self frequency recovery control, a compensation control scheme was developed, as shown in Fig. 2. The main purpose of the compensation control is not to reduce transient frequency difference but to reduce the active power sharing error. Even if the transient frequency difference is small, the active power difference may be large since it depends on time of integration of the frequency difference and magnitude of line impedance. The output active power deviation of the ith DG is given by 
$\Delta \mathrm{Pi}$, dis $=\mathrm{Pi}-\mathrm{Pi}$, dis

The aggregate of all DG units can be found by summing the contributions from each unit; i.e.,

$\Delta \mathrm{Pdis}$, tot $=\sum_{i=1}^{N} \Delta P i$, dis.

Where $\mathrm{N}$ is the number of DG units participating in active power sharing. Because the objective of compensation control is to share the active power according to the ratio of the droop coefficients (i.e., $\mathrm{ml}, \ldots, \mathrm{mN}$ ), $\Delta$ Pdis, tot should be distributed among the DG units considering the droop coefficients. Hence, the parameter ci (see Fig. 2) was determined as follows:

$c_{i}=\frac{1 / m_{i}}{\sum_{j=1}^{N}\left(1 / m_{i}\right)}$.

By multiplying ci by $\Delta$ Pdis, tot, we obtain the contribution of the ith DG unit to frequency recovery. Consequently, the compensation recovery control can be expressed as

$\Delta \mathrm{fi}, \mathrm{com}=\mathrm{kc} \int\left(c_{i} \Delta \mathrm{Pdis}\right.$, tot $-\Delta \mathrm{Pi}$, dis $\left._{i}\right) \mathrm{dt}$.

To communicate between the CC and DG units, and to assign $\Delta$ Pdis, tot, a communications system is required, which may decrease system reliability. Ordinarily, the switch is connected to node b; in this state, the communications system is unnecessary and all DG units are controlled only using droop control and self-frequency control. If the microgrid operator decides to offset the active power sharing error, for all DG units, the switches are changed to node a by the CC. Using this switch, the communications system is utilized only when the microgrid operator requires it or it can be automatically operated by periodical signal. Either way, the communication system failure does not significantly harm the system stability since it only concerns the active power sharing error.

By combining these three control schemes, the reference output frequency of the ith DG unit can be expressed as

$\mathrm{Fi}$, ref $=$ fnom $+\operatorname{mi}(\mathrm{Pi}$, dis $-\mathrm{Pi})+\mathrm{kf} \int($ fnom fi)dt $+\mathrm{kc} \int($ cisPdis, tot $-\Delta P i, d i s) d t .(8)$

To verify the effectiveness of the proposed control method for DG units, case studies were implemented.
Table1 lists the simulation parameters for all scenarios.

TABLE1

ASSOCIATED PARAMETERS FOR POWER STAGE AND CONTROL OF THE DG UNIT

\begin{tabular}{|c|c|c|c|}
\hline Parameters & Values & Parameters & Value \\
\hline $\boldsymbol{L}_{\boldsymbol{f}}(\boldsymbol{m H})$ & 50 & $\begin{array}{c}\text { Nominal } \\
\text { frequency } \\
f_{\text {nom }}(\mathrm{Hz})\end{array}$ & 50 \\
\hline $\boldsymbol{r}_{\boldsymbol{f}}(\Omega)$ & 0.01 & $\begin{array}{c}\text { P-f droop } \\
\text { coefficient } \mathrm{m} \\
\text { (rad/wattsec) }\end{array}$ & 1 \\
\hline $\boldsymbol{c}_{\boldsymbol{f}}(\mu \boldsymbol{F})$ & 20 & $\begin{array}{c}\text { Q-v droop } \\
\text { coefficient } \mathrm{n} \\
\text { (v/var) }\end{array}$ & 0.05 \\
\hline $\boldsymbol{L}_{\text {line1 }}(\boldsymbol{m H})$ & 1 & Integral gain kf & 20 \\
\hline $\boldsymbol{L}_{\text {line2 }}(\boldsymbol{m H})$ & 1.5 & Integral gain kc & 10 \\
\hline
\end{tabular}

\section{SIMULATION AND RESULTS}

The proposed improved reactive power sharing strategy is verified with MATLAB/Simulink. In the simulations a microgrid with two DG systems, as shown in Fig. 6, is employed. The associated parameters for power stage and control of the DG unit are listed in Table I. Also, in order to facilitate the observation of the reactive powers haring, the two DG units are designed with same power rating and different line impedances. The DG line current and filter capacitor voltage are measured to calculate the real and reactive powers.

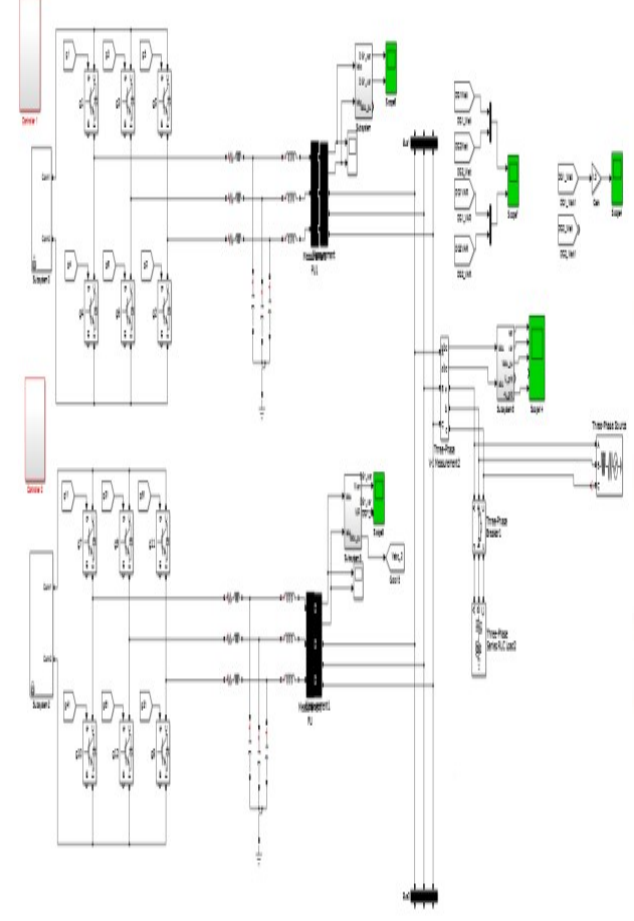

Fig 6. Configuration of the microgrid test system model 


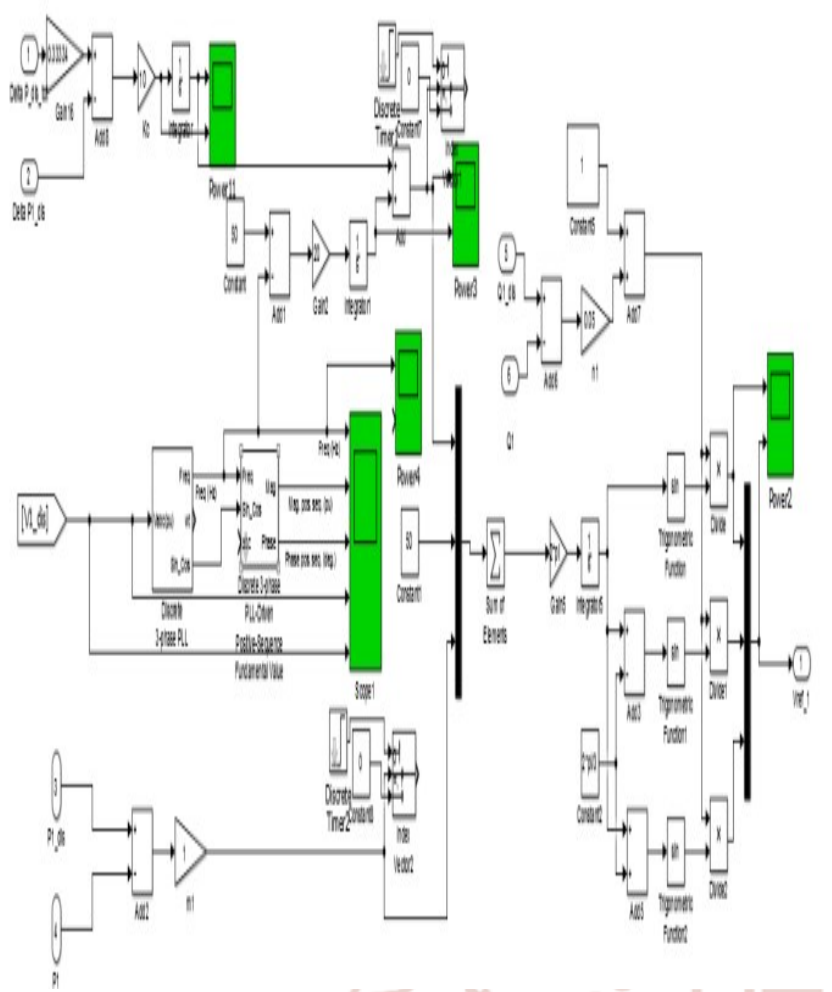

Fig. 7 Proposed control scheme for distributed generation DG unit

\section{Case1: Power Sharing Accuracy Improvement:}

Two identical DG units operate in parallel with the proposed voltage droop control. Fig. 8 illustrates the reactive power sharing performance of the two DGs. Before $\mathrm{t}=0.05 \mathrm{~s}$, the sharing error reduction operation and voltage recovery operation are disabled. There exists an obvious reactive power sharing error due to the unequal voltage drops on the feeders. After $\mathrm{t}=0.05 \mathrm{~s}$, the reactive power sharing error reduction operation is performed, and it is clear that the reactive power sharing error converges to zero gradually. After $\mathrm{t}=0.1 \mathrm{~s}$, the voltage recovery operation is performed. It can be observed that the output reactive power increases but the reactive power sharing performance does not degrade. Fig. 8 shows the corresponding output voltages. It can be observed that the output voltages decrease during the sharing error reduction operation, while the voltage recovery operation ensures that DG output voltage amplitudes can restore back nearby to the rated value shows in fig.9. The whole process of adjustment can be done steadily in a relatively short period of time.

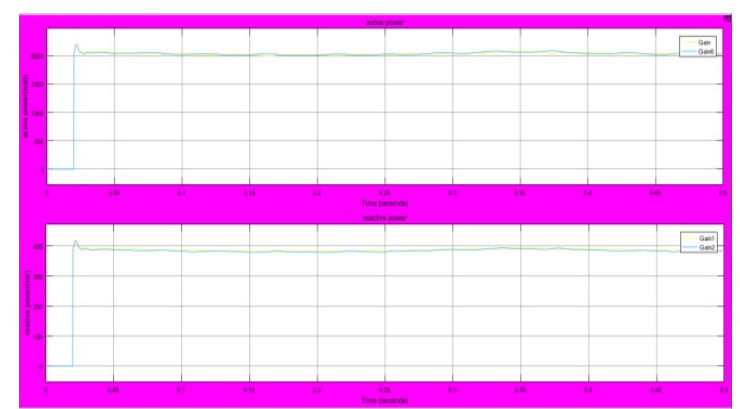

Fig.8. Simulated active and reactive power sharing performance in a networked microgrid (compensated is activated at $0.5 \mathrm{sec})$

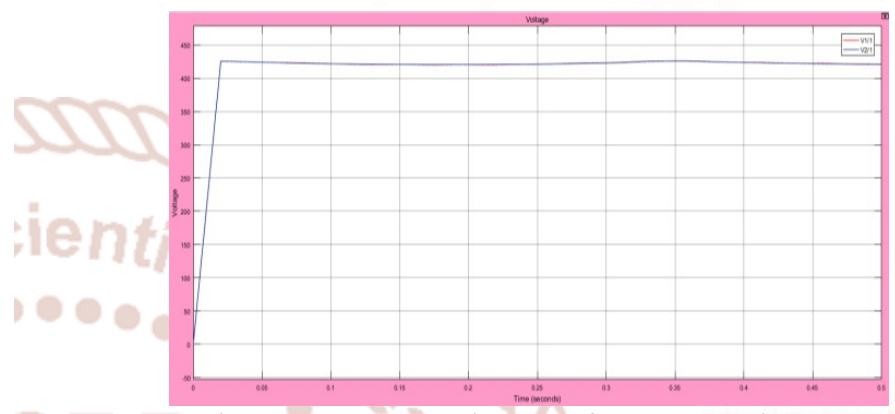

Fig. 9 Output voltage of DG1 And DG2

\section{Case 2: Effect of the Communication Delay:}

To test the sensitivity of the proposed improved droop control to the synchronized signal, a $0.02-\mathrm{s}$ delay is intentionally added to the signal received by DG1 unit at $\mathrm{t}=0.25 \mathrm{~s}$ and the simulation results are shown in Fig. 10. Compared to the case 1 in Fig 8 and 9, a small disturbance appears in both the reactive and active power, while the voltage recovery operations are still able to ensure that the DG unit can deliver the expected reactive power. After $\mathrm{t}=0.25 \mathrm{~s}$, the active and reactive power sharing errors are almost zero. Therefore, the proposed reactive power sharing strategy is not sensitive to the communication delay. Then, it is illustrated that it is robust to some small communication delays.

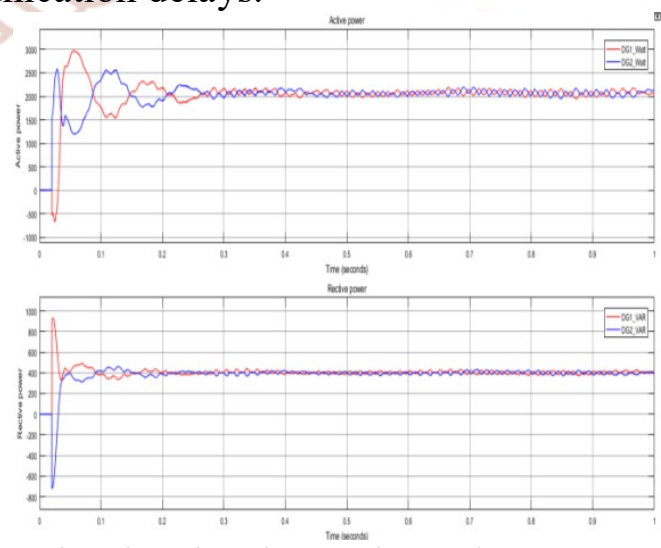

Fig.10 Simulated active and reactive power when 0.02-s time delay occurs in synchronization signal of DG1 unit. 


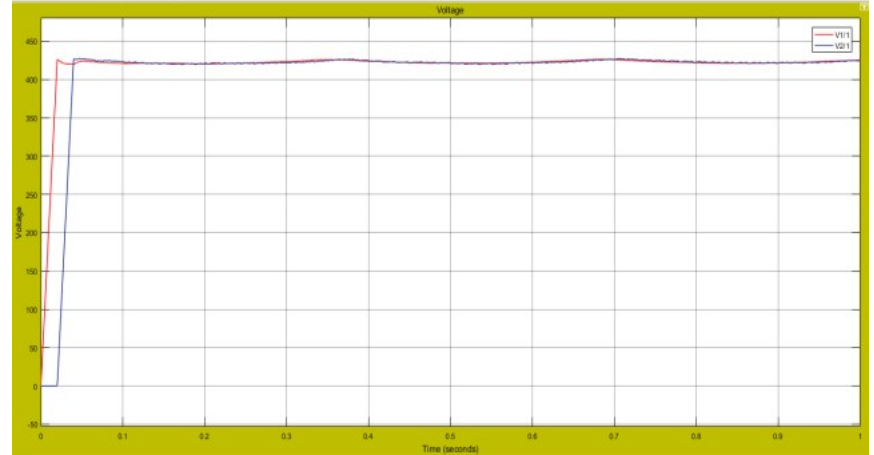

Fig.11 Output voltage of DG1 And DG2when 0.02-s time delay occurs in synchronization signal of DG1 unit.

\section{Case 3: Effect of Load Change:}

In order to test the effect of load change with the proposed method, the active load increases about $1.5 \mathrm{~kW}$ and the reactive load increases about $0.5 \mathrm{kVarat} \mathrm{t}=0.25 \mathrm{~s}$, and at $\mathrm{t}=0.25 \mathrm{~s}$ the active load decreases about $1.5 \mathrm{~kW}$ and the reactive load decreases about $0.5 \mathrm{kVar}$. The corresponding simulation results are shown in Figs. 12 and 14. As can be seen, a large reactive power sharing deviation appears at $\mathrm{t}=0.25 \mathrm{~s}$ and $\mathrm{t}=0.25 \mathrm{~s}$. However, the deviation becomes almost zero after a while.Fig. 13 and 15 shows no change in output voltage.

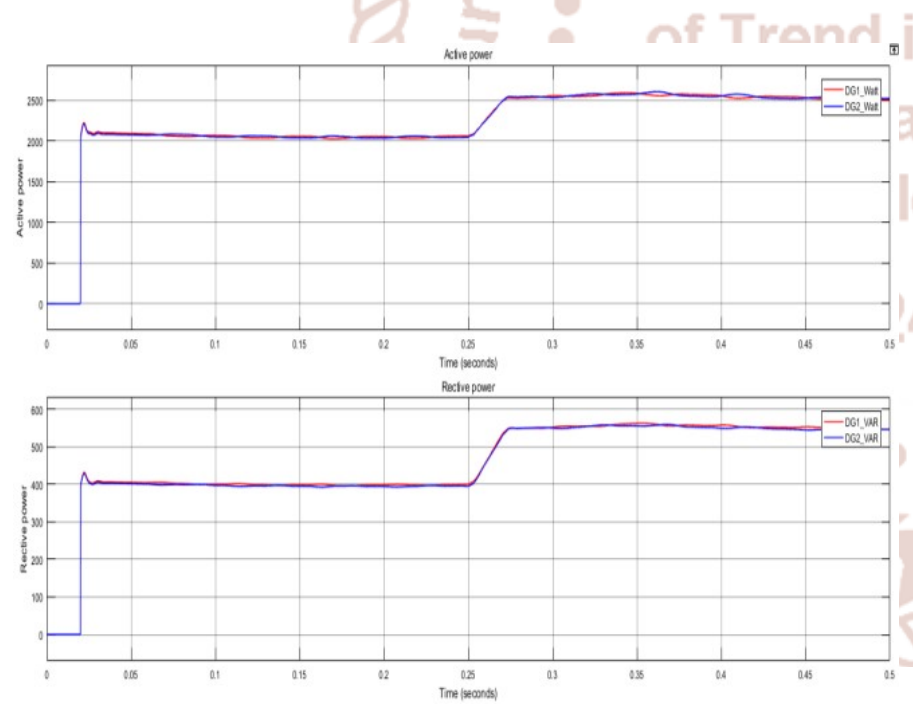

Fig.12.simulated active and reactive power when load is increased

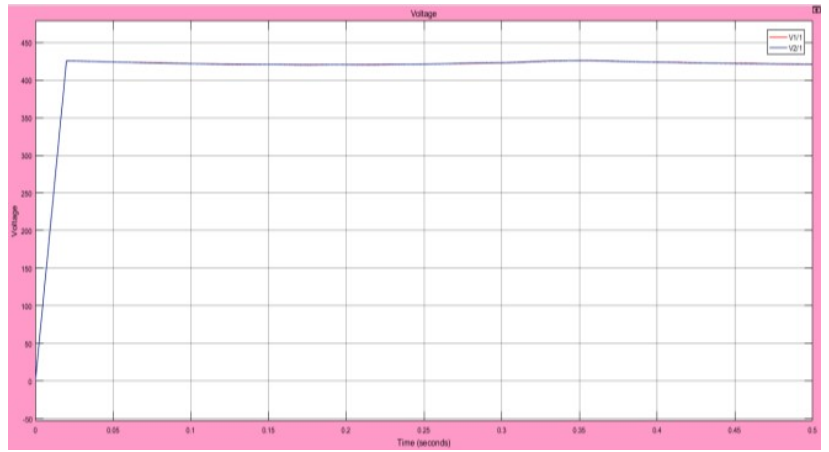

Fig.13. Output voltage of DG1 And DG2 when load is increased

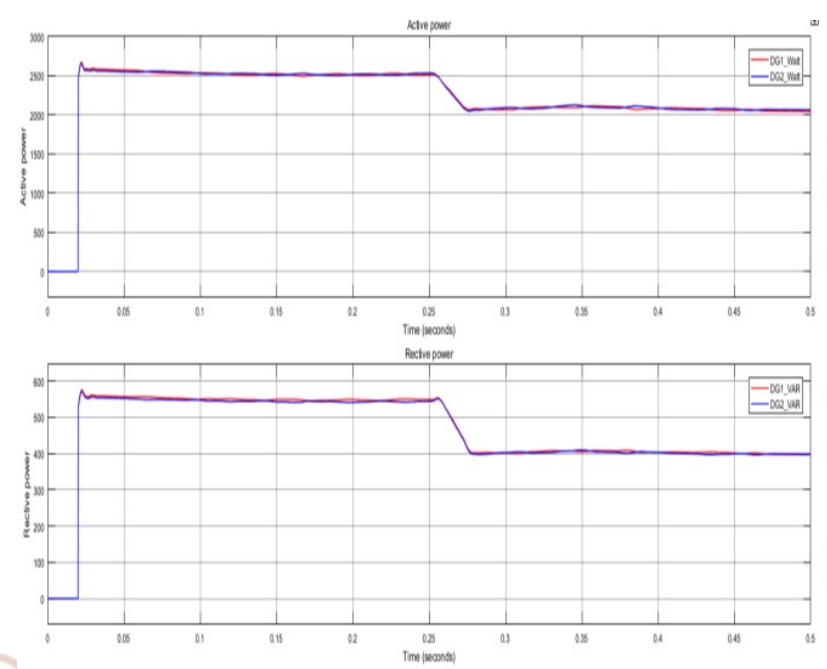

Fig 14. simulated active and reactive power when load is decreased

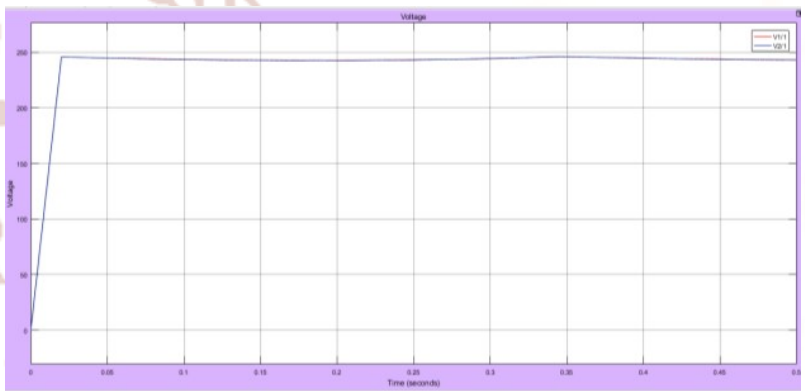

Fig.15 Output voltage of DG1 And DG2when load is decreased

\section{CONCLUSION AND FUTURE SCOPE}

A control strategy to improve reactive power sharing in an islanded microgrid has been proposed in this paper. The proposed control strategy employs the communication network to exchange the information among the DG units to tune the adaptive virtual impedances in order to compensate the mismatch in feeder impedances. The advantage of the control strategy is that it does not require any information of the feeder impedances and can be straightforward to implementing in the practice. Moreover, the proposed technique can also work well even when the transmission line is interrupted and the error of the power sharing is always low in the allowed limits. Simulation results shows that the frequency was restored almost immediately following frequency deviation using self-frequency control and also using compensation and droop control active and reactive power was shared accurately and effectiveness of the proposed method was verified.

In the future works, the proposed microgrid can be simulated with more number of DG sources and higher rating loads which can be installed for that configuration. Four to five DG sources can be 
considered for this kind of study. Another area for the future work is the communications delay. Although a communications system is required only for as short duration (to implement compensation control), the communications delay may affect the control stability. Hence, determining the appropriate integral gain is desirable, which may avoid instabilities in the compensation control method.

\section{REFERENCES}

1. Jinwei He and Yun Wei Li, An Enhanced Micro grid Load Demand Sharing Strategy, IEEE-2012.

2. K. D. Brabandre, B. Bolsens, J. V. D. Keybus A. Woyte, J. Drisen and R. Belmans , A voltage and frequency droop control method for parallel inverters, IEEE Trans. Power Electron., vol. 22, no. 4, pp. 1107-1115, Jul.2007.

3. Y. Li and Y. W. Li, Power management of inverter interfaced autonomous microgrid based on virtual frequency-voltage frame, IEEE Trans. Smart Grid., vol. 2, no. 1, pp. 30-40, Mar. 2011.

4. C.-T. Lee, C. -C. Chu, and P.-T. Cheng, A new droop control method for the autonomous operation of distributed energy resource interface converters, in Proc. Conf. Rec. IEEE Energy Convers. Congr. Expo., Atlanta, GA, 2010, pp. 702-709.

5. J. M. Guerrero, L. G. Vicuna, J. Matas, M. Castilla, and J. Miret, Output impedance design of parallel-connected UPS inverters with wireless load sharing control, IEEE Trans. Ind. Electron., vol. 52, no. 4, pp. 1126-1135, Aug. 2005.

6. Y. W. Li and C.-N. Kao, An accurate power control strategy for power electronics-interfaced distributed generation units operation in a low voltage multi bus microgrid, IEEE Trans. Power Electron., vol. 24, no. 12, pp. 2977-2988, Dec. 2009.

7. J. He and Y. W. Li, Analysis, design and implementation of virtual impedance for power electronics interfaced distributed generation, IEEE Trans. Ind. Appl., vol. 47, no. 6, pp. 2525-2538, Nov./Dec. 2011.

8. E. A. A. Coelho, P. C. Cortizo, and P. F. D. Garcia, Small-signal stability for parallelconnected inverters in stand-alone AC supply systems, IEEE Trans. Ind. Appl., vol. 38, no. 2, pp. 533-542, Mar./Apr. 2002.

9. Y. W. Li, D. M. Vilathgamuwa, and P. C. Loh, Design, analysis and real- time testing of a controller for multi bus microgrid system, IEEE Trans. Power Electron, vol. 19, no. 5, pp. 11951204, Sep. 2004.

10. Han, Hua, Yao Liu, Yao Sun, Mei Su, and Josep M. Guerrero. "An improved droop control strategy for reactive power sharing in islanded microgrid." IEEE Transactions on Power Electronics 30, no. 6 (2015):

11. S.-J. Ahn et al., "Power-sharing method of multiple distributed generators considering control modes and configurations of a microgrid," IEEE Trans. Power Del., vol. 25, no. 3, pp. 2

12. Milczarek, Adam, Mariusz Malinowski, and Josep M. Guerrero. "Reactive power management in islanded microgrid-Proportional power sharing in hierarchical droop control." IEEE Transactions on Smart Grid 6.4 (2015): 1631-1638.

13. Kumar, K., N. Ramesh Babu, and K. R. Prabhu. "Design and Analysis of an Integrated Cuk-SEPIC Converter with MPPT for Standalone Wind/PV Hybrid System."International Journal of Renewable Energy Research (IJRER) 7.1(2017): 96-106.

14. Moussa, Hassan, et al. "Optimal Angle Droop for Power Il Sharing Enhancement with Stability Improvement in Islanded Microgrids." IEEE Transactions on Smart Grid (2017).

15. SenV. Sivanagaraju, K. Kumar, K. Rajasekharachari. Performance Comparison of Variable Speed Induction Machine Wind Generation System with and Without Fuzzy Logic Controller. Int J Innov R Devel. 2013

16. Zhu, Yixin, et al. "A virtual resistance based reactive power sharing strategy for networked microgrid." Power Electronics and ECCE Asiam (ICPE-ECCE Asia), 2015 9th International Conference on. IEEE, 2015.

17. Rajasekharachari, K., and K. Shalini, Kumar. K and SR Divya. Advanced Five Level-Five Phase Cascaded Multilevel Inverter with SVPWM Algorithm. Int J Electric Engi \& Technol. 2013;

18. Mahmood, Hisham, Dennis Michaelson, and Jin Jiang. "Reactive power sharing in islanded microgrids using adaptive voltage droop control." IEEE Transactions on Smart Grid 6.6(2015):

19. Kim, Yun-Su, Eung-Sang Kim, and Seung-Il Moon. "Distributed generation control method for active power sharing and self-frequency recovery in an islanded microgrid." IEEE Transactions on Power Systems 32.1 (2017): 544-551. 